\title{
Letter From the Guest Editor
}

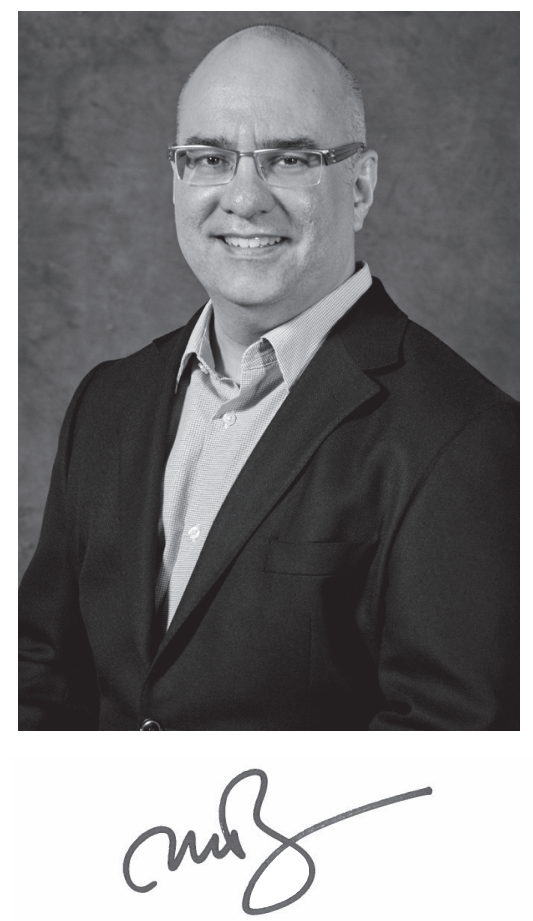

Matthew J. Bowes MD

Guest Editor

Public sector budgets shrink and expectations grow. Technology provides new investigative tools that must be studied, validated, and then applied. Standards, guidelines, and position papers of various kinds are promoted, and perhaps embedded into policy. Every day, another drug of abuse surfaces: its effects on human physiology must be understood, and methods must be developed for its detection. There is too much stuff to do, and too few of us to do it.

It is easy to list the challenges of modern medicolegal death investigation, and to be consumed by the daily work flow. The service we provide can feel like a treadmill.
The first casualty of over-work may be the loss of our connection to the impact that we make on the lives of the people we serve. And we do make a tremendous impact on society: the articles in this issue of Academic Forensic Pathology leave little doubt about this. It is our hope that these articles will serve as a general reminder of this impact. But why read them?

Selfishly, I think it is important to take the time to situate ourselves in the broader medicolegal and public health context. As professionals, we value selfless hard work, and in so doing, we underemphasize the importance of our own mental well-being. Connecting with all the positive ways we help people is a power- 
ful way to improve our morale. If there were no other reason to read this issue, then this would be enough in my opinion. But there are other, more practical reasons to pay attention to what is written here.

Medicolegal death investigation is administered as a service of government, and government services must have a demonstrable impact on the lives of the taxpayers who provide our funding. As stewards of the public purse, we can and ought to maximize the value that taxpayers achieve from their investment. This means that the activity and the data we generate should be used to its maximum good effect, and by this we mean all the many ways that justice can be served, health can be promoted, and death can be prevented.

The authors of the papers in this issue have found or are developing exciting new ways to serve the public and maximize the value that they deliver to the taxpayers in their jurisdiction. As I read these articles, I challenged myself: does my service extract the most value from the data we collect? Are we taking every opportunity to save or improve lives and advance the cause of public health? Are there agencies of government that could benefit from a closer partnership with the medical examiner service, but are not?

Every Chief Medical Examiner and every forensic pathologist who has an interest in administration knows that the answers to these questions have a practical importance. Government services that provide good value for society may be rewarded with sustainable funding. Those services that do not continually demonstrate relevance wither and die, and (it might be argued) ought to do so.

It has been a great honor to serve as Guest Editor of this issue. I hope that it will remind us of the impact we make and inspire us to improve the service we deliver. 